\title{
Practical Local Geoid Modelling of Benin City, Nigeria from Gravimetric Observations Using the Modified Stokes Integral
}

\author{
Oduyebo, O. F. *; Ono M. N. and Eteje, S. O.
}

\begin{abstract}
Department of Surveying and Geoinformatics, Nnamdi Azikiwe University, Awka, Nigeria
*Corresponding Author: jimioduyebo@yahoo.com
\end{abstract}

\begin{abstract}
The geometric heights obtained from GNSS observations cannot be used for engineering works as they are not reduced to the geoid. This study presents practical local geoid modelling from gravimetric observations using the modified Stokes integral for engineering applications in Benin City. A total of 52 points were observed with GNSS receivers and a gravimeter to respectively obtain their positions and absolute gravity values. The theoretical gravity values of the points were computed on the Clarke 1880 ellipsoid to obtain their local gravity anomalies. The modified Stokes integral was applied to compute the geoid heights of the points. The combined topographic effect was applied to the computed geoid heights of the points to obtain their precise geoid heights. The mean of the precise geoid heights of the points was computed to obtain the local gravimetric geoid model of the study area. The determined geoid model was validated for its reliability as well as the accuracy using the RMSE index. It is recommended that the use of assumed, as well as handheld GPS receiver heights for engineering works should be totally abolished as this study has established the local geoid model of Benin City.
\end{abstract}

Keywords-gravimetric observations, integration, local geoid, modelling, modified Stokes integral.

\section{INTRODUCTION}

The geoid is an equipotential (level) surface of the earth's gravity field which coincides with mean sea level (MSL) in the open oceans. As such, the geoid provides a meaningful reference frame for defining heights. The importance of accurately modelling the geoid has increased in recent years with the advent of satellite positioning systems such as the Global Navigation Satellite System (GNSS). GNSS provides height information relative to a best-fitting earth ellipsoid rather than the geoid (Seager et al., 1999; Yilmaz and Arslan, 2006). To convert ellipsoidal heights derived from GNSS to conventional (and meaningful) orthometric heights, the relationship between the geoid and the ellipsoid must be known (Kotsakis and Sideris, 1999; Yilmaz and Arslan, 2006). The fundamental relationship that ties ellipsoidal heights obtained from Global Navigation Satellite System (GNSS) measurements and heights with respect to a vertical datum established using spirit levelling and gravity data, is to the first approximation given by (Heiskanen and Moritz, 1967; Krynski and Lyszkowicz, 2006; Oluyori et al., 2018) as:

$$
h=H+N
$$

Where $h$ is the ellipsoidal height, $H$ is the orthometric height, and $N$ is the geoid undulation. Figure 1 shows the relationship between the orthometric, geoid and ellipsoidal heights.

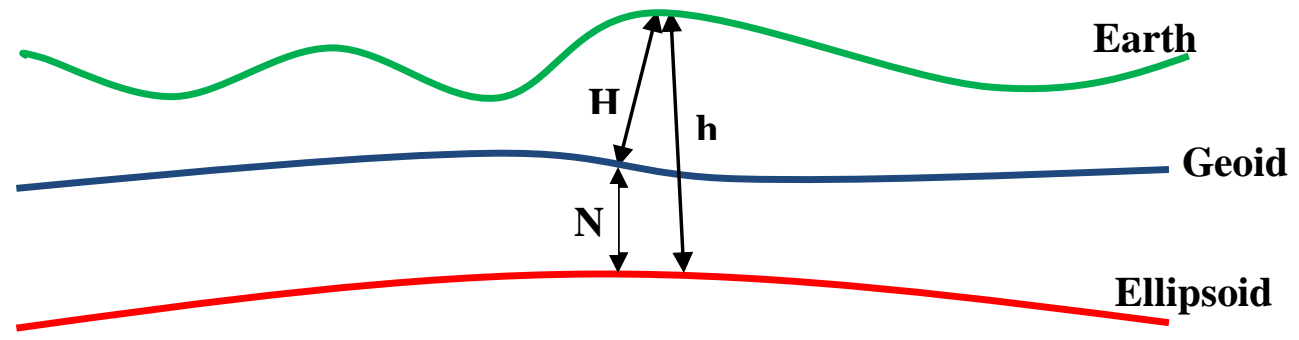

Fig: 1: Relationship between Orthometric, Geoid and Ellipsoidal Heights Source: Eteje et al. (2018) 
Geoid Modelling is carried out by various methods such as the gravimetric, geometric, Astro-geodetic, transformation and gravimetric-geometric methods. The gravimetric method can be carried out by the application of the well-known Stokes-integral, equation (2) and the use of accurately determined absolute gravity data (Heiskanen and Moritz, 1967, Eteje, 2015 and Eteje et al., 2018).

$$
N=\frac{R}{4 \pi \gamma} \iint_{\sigma} \Delta g S(\psi) d \sigma
$$

Where $N$ is geoid undulation, $\Delta g$ is gravity anomaly, $S(\psi)$ is Stokes function, $\gamma$ is normal gravity on the reference ellipsoid and $R$ is mean radius of the earth.

The application of the Stokes integral for local geoid modelling requires the solving/integration of the modified Stokes integral given in equation (2). Here, the geoid height of each point in a study area is computed and corrected for the combined topographic effect to obtain a precise geoid height of the point. The geoid model of the area of study is the average, as well as the mean of the geoid heights of the selected/observed points. The accuracy of the model is obtained using the Root Mean Square Error (RMSE) index. The RMSE of the model is computed by comparing the results obtained from physical measurements carried out on some selected points with their corresponding results from the determined geoid model.

The geometric heights obtained from GNSS observations cannot be used for engineering works such as the installation of communication mast, road construction, building construction, the building of crude oil facilities, line and underground drainage construction, bridges, viaduct and tunnel constructions. The geometric, as well as ellipsoidal heights can be converted to practical heights reduced to the geoid, as well as the mean sea level. The conversion of the geometric heights of points to orthometric heights requires the knowledge of the geoidellipsoid separations of the points. Orthometric heights are required in engineering constructions to decide on suitable gradients to direct the flow of water and to decide on various levels of proposed constructions. With orthometric height, water can flow from one point to another while with ellipsoidal height, it is impossible. Benin City is the capital of Edo State. It is a developing area which requires a geoid model for meaningful and physical developments. Therefore, this study determines the local geoid model of Benin City from gravimetric observations using the modified Stokes' integral.

\subsection{The Study Area}

Benin City is the capital of Edo State in Southern Nigeria. It is a City approximately 40 kilometres north of the Benin River. The City is also linked by roads to Asaba, Sapele, Siluko, Okene, and Ubiaja and is served by air and the Niger River delta ports of Koko and Sapele. The City is made up of three Local Government Areas, Oredo LGA, Ikpoba Okha LGA and Egor LGA. It has a total population of $1,749,316$ according to $2019 \mathrm{NPC}$ projection. It covers a total area of about $1,204 \mathrm{~km}^{2}$. Benin City is bounded by UTM zone 31 coordinates $660000 \mathrm{mN}$ and $712500 \mathrm{mN}$, and $770000 \mathrm{mE}$ and $815000 \mathrm{mE}$. Figures $2 \mathrm{a}$ and $\mathrm{b}$ show the maps of the study area.

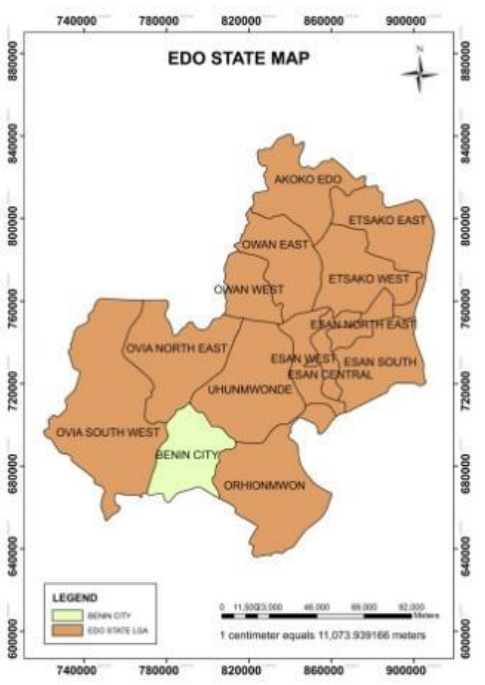

Fig. 2a: Map of Edo State

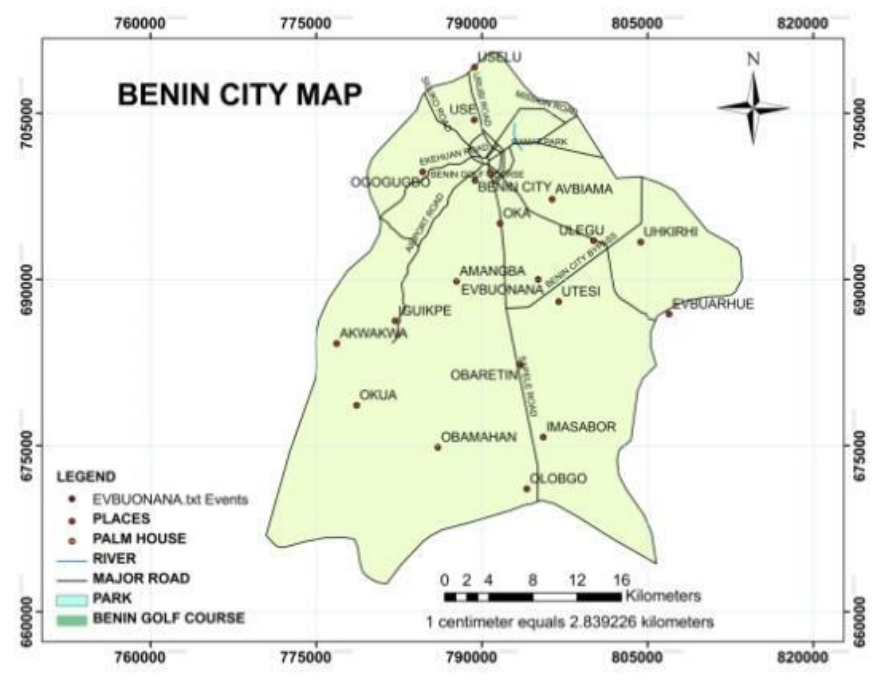

Fig. 2b: Map of Benin City

Source: Ministry of Lands and Surveys, Benin City 


\subsection{Integration of Stokes's Formula}

According to Eteje et al. (2018), using the modified Stokes integral given in equation (2), the geoid heights of points can be computed if their gravity anomalies and

$$
N=\frac{r \Delta g}{8 \gamma}\left(\begin{array}{l}
\left.-6 \sin ^{2} \psi_{o} \ln \left\{\sin \left(\frac{\psi_{o}}{2}\right)+\sin ^{2}\left(\frac{\psi_{o}}{2}\right)\right\}+16 \sin \left(\frac{\psi_{o}}{2}\right)+12 \sin ^{2}\left(\frac{\psi_{o}}{2}\right)\right) \\
-24 \sin ^{3}\left(\frac{\psi_{o}}{2}\right)-12 \sin ^{4}\left(\frac{\psi_{o}}{2}\right)-4 \cos \psi_{o}+5 \cos 2 \psi_{o}-1
\end{array}\right)
$$

Where $N$ is the geoidal height of individual point, $\psi_{o}$ is the surface spherical radius, $\gamma$ is the theoretical as well as normal gravity, $\Delta g$ is the gravity anomaly and $r=R$ is the mean radius of the earth. So, the computation of the geoid heights of points using equation (3) requires the use of the surface spherical radius, $\psi_{o}$, theoretical, as well as normal gravity values, $\gamma$, gravity anomalies, $\Delta g$, and the mean radius of the earth, $r=R$ of the points.

\subsection{Surface Spherical Radius Computation}

The surface spherical radius, $\psi_{o}$ is computed as (Shrivastava et al., 2015)

$$
\cos \psi=\sin \varphi \sin \varphi^{1}+\cos \varphi \cos \varphi^{1} \cos \left(\lambda^{1}-\lambda\right)
$$

geographic coordinates are known. Featherstone and Olliver (1997) gave the integration of equation (2), as well as the Stokes integral as

Where,

$$
g_{\text {TClarkel } 880(B)}=9.78051938\left(\begin{array}{l}
1+0.005247466 \sin ^{2} \varphi \\
-0.000008785 \sin ^{2} 2 \varphi
\end{array}\right) \mathrm{ms}^{-2}
$$

Where,

$$
\begin{aligned}
& g_{\text {TClarke1880 }}=\text { Theoretical gravity on the Clarke } \\
& 1880 \text { ellipsoid } \\
& \varphi=\text { Station latitude }
\end{aligned}
$$

\subsection{Gravity Anomaly Computation}

The gravity anomaly, $\Delta g$, is the difference between the observed gravity value $(g$ ) reduced to the geoid, and a normal, or theoretical, computed gravity value $\left(\gamma_{o}\right)$ at the mean earth ellipsoid, where, the actual gravity potential on the geoid equal the normal gravity potential at the ellipsoid, at the projection of the same terrain point on the geoid and the ellipsoid respectively, that is (Dawod, 1998 and Eteje et al., 2019)

$$
\Delta g=g-\gamma_{o}
$$

Considering the nature of the topography of the earth surface, which is irregular in shape, there are two basic types of gravity anomalies (free air and Bouguer anomalies). In this study, it was only the free air correction that was applied. $\varphi=$ Mean latitude of the points

$\varphi^{1}=$ Latitude of individual point

$\lambda=$ Mean longitude of the points

$\lambda^{1}=$ Longitude of individual point

\subsection{Theoretical Gravity Computation}

To obtain the local gravity anomalies of points in a study area, the normal, as well as the latitude gravity, is computed on a specified ellipsoid. That is, the ellipsoid adopted for geodetic computation in the area or region of study. Eteje et al. (2018) gave the model for the computation of the theoretical gravity on the Clarke 1880 ellipsoid as

\subsection{Free Air Correction}

This is the first step for reducing topography effects. It simply corrects for the change in the elevation of the gravity meter, considering only air (hence a free-air) being between the meter and selected datum. According to Aziz et al. (2010), this correction is added to the observed gravity because the increased radial distance of the station from the centre of the Earth results in a lower observed gravity value than if the station were at the local datum. The formula to calculate the magnitude of the reduction in practice is given by Eteje et al. (2019) as

$$
\begin{aligned}
g_{F A} & =-\frac{2 g}{r} H_{s}=-308.6 H \mu G a l \\
& =-0.3086 \mathrm{HmGal}
\end{aligned}
$$

Where,

$$
\begin{aligned}
& H=\text { Station orthometric height in metres } \\
& g=\text { Mean value of gravity }(980500 \mathrm{mGal}) \\
& r=\text { Mean radius of the Earth }
\end{aligned}
$$

\subsection{Mean Radius of the Earth Computation}

The mean radius of the earth, $\mathrm{r}=R$ was computed using:

$R=\sqrt{M N}$ 
Where $M$ is the radius of curvature along the meridian section and $N$ is the radius of curvature in prime vertical. The formula for computation of the radius of curvature in prime vertical, $N$ is given as (Ono, 2009)

$$
N=\frac{a}{\left(1-\left(2 f-f^{2}\right) \sin ^{2} \varphi\right)^{1 / 2}}=
$$

while that for computation of the radius of curvature in meridian section, $M$ is given as (Kotsakis, 2008)

$$
M=\frac{a\left(1-e^{2}\right)}{\left(1-e^{2} \sin ^{2} \varphi\right)^{3 / 2}}
$$

Where,

$$
\begin{aligned}
& a=\text { Semi-major axis } \\
& \varphi=\text { Latitude of an observation point } \\
& e^{2}=2 f-f^{2}=\text { Eccentricity squared (Eteje } e t \\
& \text { al., 2019) } \\
& f=\frac{a-b}{a}=\text { Flattening } \\
& b=\text { Semi-minor axis }
\end{aligned}
$$

\subsection{Combined Topographic Effect Computation}

To obtain a precise geoid height of a point, the combined topographic effect is calculated and applied to the computed geoid height of the point. The formula for the computation of the combined topographic effect, $\delta N_{\text {Comb }}^{\text {Topo }}$ is given as (Sjöberg, 2000 and KuczynskaSiehien et al., 2016):

$$
\delta N_{\text {Comb }}^{\text {Topo }}=-\frac{2 \pi G \rho}{\gamma}\left[H^{2}+\frac{2}{3 R} H^{2}\right]
$$

Where $G$ is the earth gravitational constant, $\rho$ is density, $R$ is the mean radius of the earth and $H$ is the orthometric height of observation point which can be obtained from the DTM of the area.

\subsection{The Geoid Model}

The final gravimetric geoid model is the mean of the geoid heights computed with equations (3) and (11) and it is obtained using

Gravimetric Geoid Model $=\frac{1}{n} \sum_{i=1}^{n} N_{i}$

Where,

$$
\begin{aligned}
& N_{i}=\text { Geoid height of points computed using } \\
& \text { equations (3) and (11), }
\end{aligned}
$$

$$
n=\text { Total number of points }
$$

\subsection{Accuracy of the Gravimetric Geoid Model}

The accuracy of the determined local gravimetric geoid model is obtained using the Root Mean Square Error, RMSE index. To evaluate the determined local gravimetric geoid model accuracy, the orthometric heights computed from the differences between the model geoid heights and ellipsoidal heights of some selected points are compared with their (the points) respective orthometric heights obtained from spirit levelling to get the residuals. The computed residuals and the total number of points are used to calculate the RMSE of the model. The Root Mean Square Error, RMSE index for the computation of gravimetric geoid model accuracy as given by Kao et al. (2017) and Eteje and Oduyebo (2018) is

$R M S E= \pm \sqrt{\frac{V^{T} V}{n}}$

Where,

$$
\begin{aligned}
& V=H_{\text {Observed }}-H_{\text {Model }} \text { (Residual) } \\
& H_{\text {Observed }}=\text { Observed Orthometric Height of Point } \\
& H_{\text {Model }}=\text { Model Orthometric Height of Point } \\
& \mathrm{n}=\text { Number of Points }
\end{aligned}
$$

\section{METHODOLOGY}

The adopted methodology was divided into different stages of data acquisition, data processing, and results presentation and analysis. Figure 3 shows the adopted methodology flow chart.

\subsection{Data Acquisition}

A total of 52 points were used in the study. The points included two primary control stations (XSU 92 and XSU 100 were respectively located in Edo College and School of Nursing premises). The other 50 points were selected along the major roads of the City (See Figure 4). Spirit levelling was carried out on 3 of the 50 points for validation purpose. GNSS observations were carried out using CHC 900 dual-frequency GNSS receivers to obtain the coordinates and ellipsoidal heights of the points. The observations were carried out relative to control station XSU 92 using the static method (See Figures 5 and 6). 


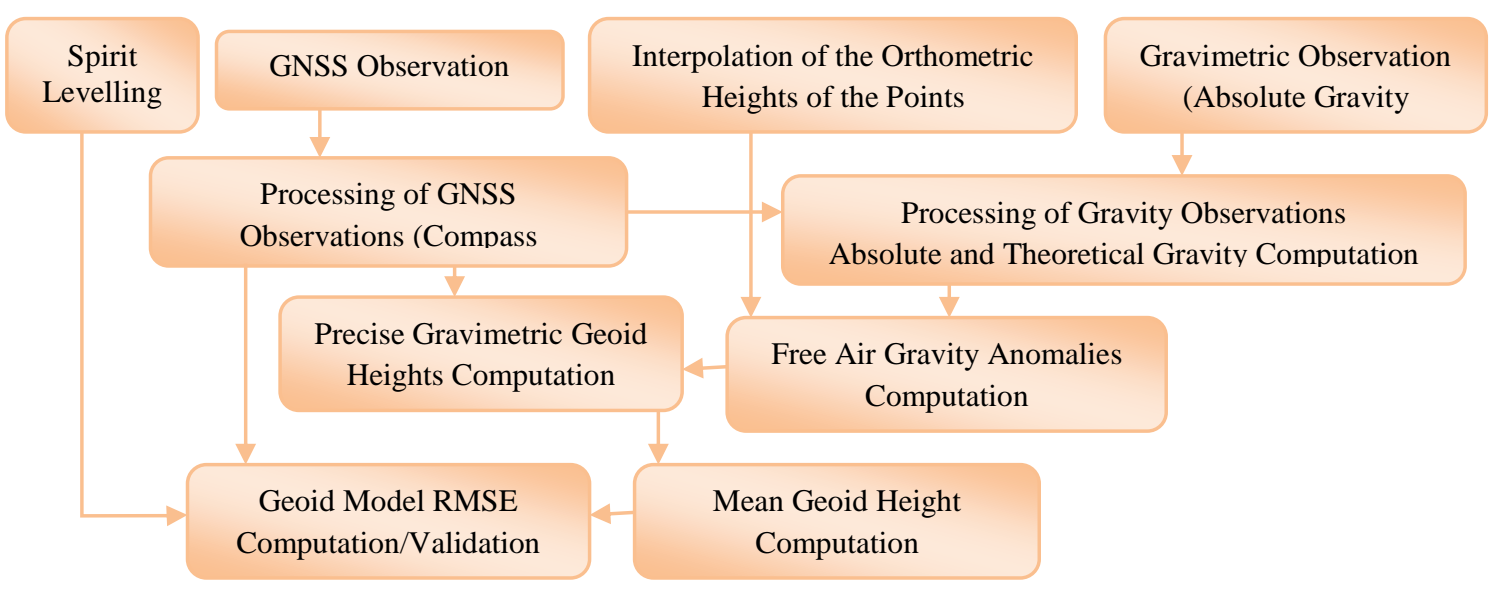

Fig 3: Flow Chart of the Adopted Methodology

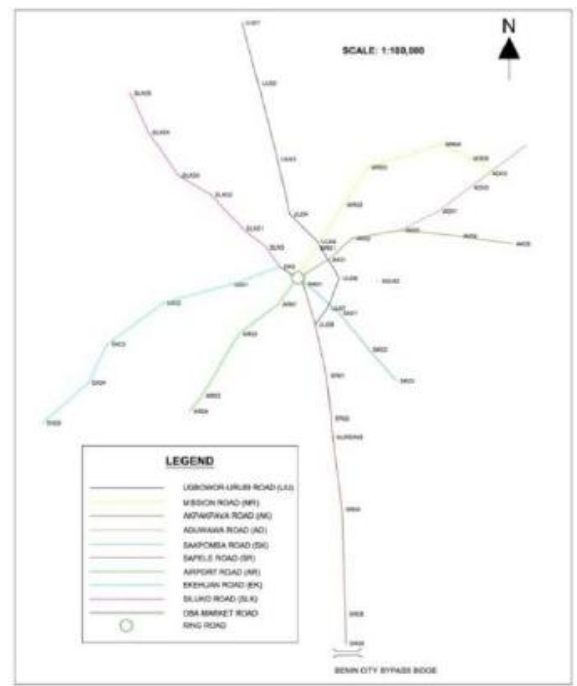

Fig 4: Selected GPS and Gravity Points

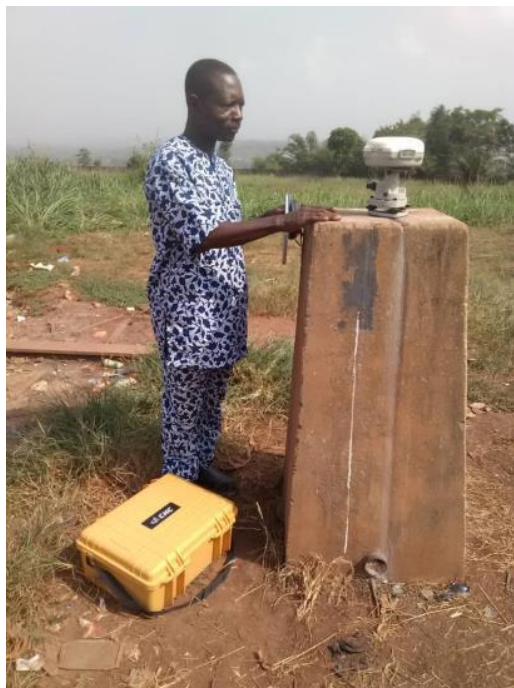

Fig. 5: Base Receiver at Control Station XSU92

The selected points were observed with a gravimeter (SCINTREX CG-5 Autograv Gravimeter) to obtain their absolute gravity values. The observations were carried by an expert, a Geophysicist from Mountain Top University, Ibafo, Ogun State. The gravity observations of the points

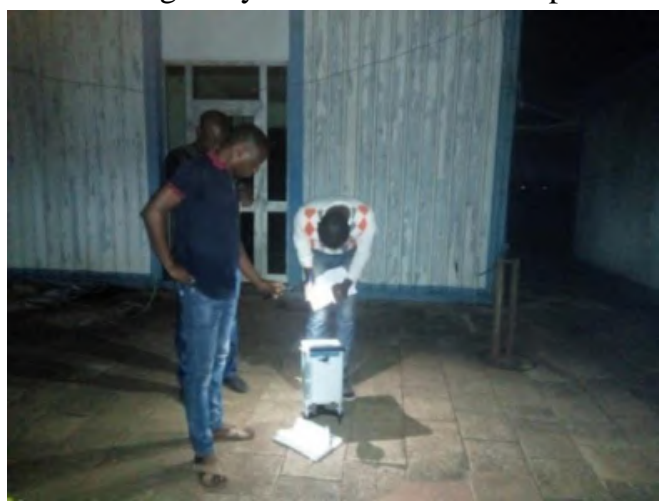

Fig. 7: Gravimeter Set over Reference Station at Benin City Airport

Spirit levelling was carried out on the 3 validation points, as well as test points using control station XSU100 as a

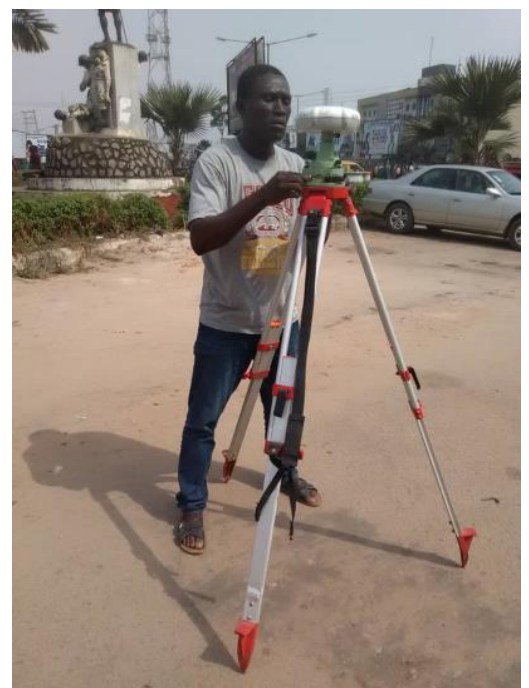

Fig. 6: Rover Receiver at One of the Selected Points (RR01) at Ring Road were carried out in seven different loops relative to a point whose absolute gravity value was known and located within the Benin City Airport premises (See Figures 7 and 8).

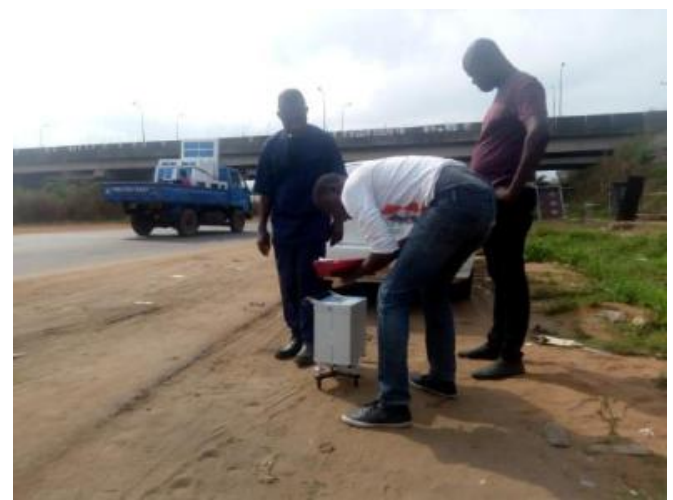

Fig. 8: Gravimeter at One of the Selected Points at Bypass along Benin-Sapele Road point of known orthometric height to obtain their practical heights. The levelling of the test points was carried out in 
two loops. The first loop started from control station XSU100 to TP1 and closed back on control station XSU100 while the second loop levelling started from TP1 through TP2 to TP3 and closed back on TP1. Figure 9 shows the validation points' levelling loops.

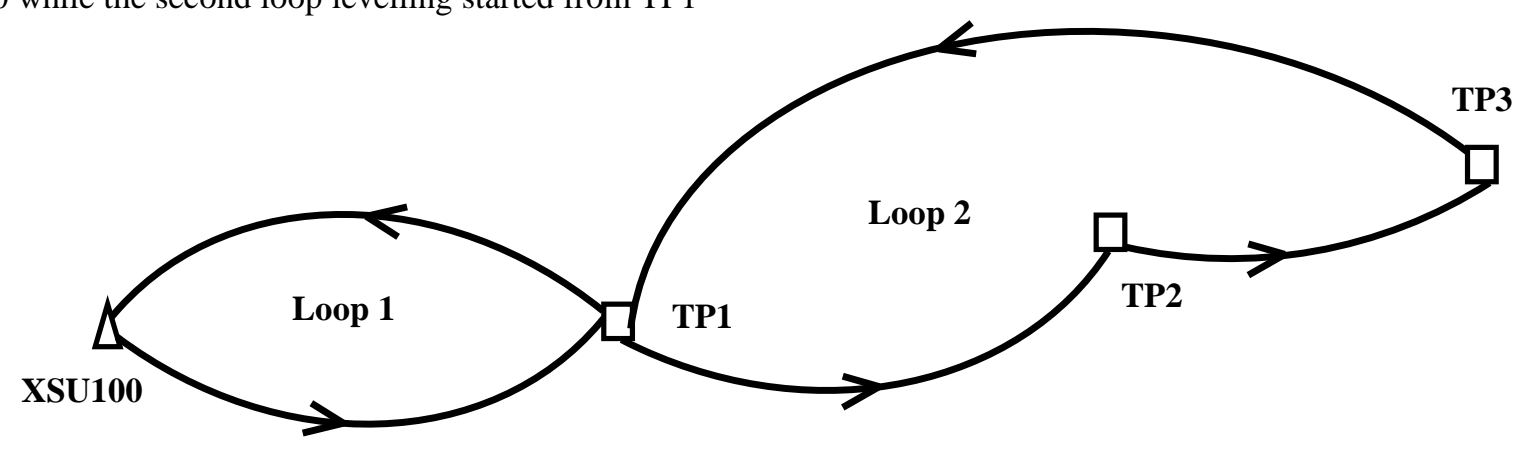

Fig. 9: Validation Points Levelling Loops

\subsection{Data Processing}

The GNSS observations were respectively downloaded and processed with HcLoader and Compass Postprocessing software to obtain the positions and the ellipsoidal heights of the points. The coordinates and the ellipsoidal heights of the points were processed in Minna datum. The gravity observations of the points were processed by the expert who carried out the observation to obtain their absolute gravity values. All the necessary corrections such as drift correction, etc were applied during the processing. The theoretical gravity values of the points were computed on the local (Minna) datum ellipsoid (Clarke 1880 ellipsoid) using the latitude coordinates of the points, as well as equation (5). The gravity anomalies of the points were computed by finding the differences between the absolute gravity values of the points and their corresponding theoretical gravity values, as well as using equation (6). The computation of the free air correction requires the application of the orthometric heights of the points. And these were obtained by interpolation using the orthometric heights and the absolute gravity values of the two primary control stations (XSU 100 and XSU 96). The orthometric heights of the points were interpolated as there was no Digital Terrain Model (DTM) of the study area. The free air correction was applied to the computed gravity anomalies of the points using equation (7). The free air and the Bouguer gravity anomalies of the points were computed but the free air gravity anomalies were used in the study. This is because the geoid heights of the two primary control stations obtained from their known orthometric and ellipsoidal heights approximated the geoid heights of the stations computed using the free air gravity anomalies, as well as equation (3). The gravimetric geoid heights of the points were computed with the geographic coordinates, free air gravity anomalies and the theoretical gravity of the points using equation (3). The computation of the gravimetric geoid heights of the points required the application of the spherical radius and the mean radius of the earth. The spherical radius and the mean radius of the earth were respectively computed using equations (4) and (8). Also, the computation of the mean radius of the earth required the computation of the radius of curvature in prime vertical and in meridian section using equations (9) and (10) respectively. The computed gravimetric geoid heights of the points using equation (3) were co-geoid heights. To obtain precise gravimetric geoid heights of the points, the combined topographic effect has to be computed and applied to the co-geoid heights. The combined topographic effect was computed using equation (11). The final local gravimetric geoid model of the study area was obtained by finding the mean of the precise geoid heights of the points using equation (12). The spirit levelling of the validation points was reduced using the height of instrument method, as well as collimation method. The RMSE, as well as the accuracy of the model, was computed by finding the square root of the mean of the differences between the model and the observed orthometric heights of the validation points and the two control stations using equations (13).

\section{RESULTS PRESENTATION AND ANALYSIS}

\subsection{Analysis of the GNSS Observation Results}

The DGPS observations were carried out to obtain the coordinates and ellipsoidal heights of the selected points. The DGPS observations were processed using Compass post-processing software. From the processing of the DGPS observations results, it was seen that the processed observations passed both the Network Adjustment Test and the X-Square (Chi-square) Test. This implied that the normal matrix generated was a regular one and inverted accordingly for the calculation of residuals. 


\subsection{Analysis of the Validation Points Levelling}

Table 1 presents the closure errors/accuracy of the two loops of the validation points levelling. The levelling of the validation points was done to obtain the orthometric heights of the validation points. The levelling was carried in two loops. The first loop started from XSU100 to TP1 and closed back on XSU100 while the second loop started from TP1 through TP2 to TP3 and closed back on TP1.
From Table 1 it is seen that the closure error of the first loop is $-0.006 \mathrm{~m}$ while the second loop closure error is $0.009 \mathrm{~m}$ which were within millimetres standard. The results were accepted as the closing errors of the two loops. The high accuracy of the levelling was as a result of the fairly flat topography of the study area, the observer's know-how and the equipment used.

Table 1: Known and Observed Heights of the Closing Stations

3.3

\begin{tabular}{|c|c|c|c|c|}
\hline Station & Description & $\mathbf{H}_{\text {(known) }}(\mathbf{m})$ & $\mathbf{H}_{\text {(observed) }}(\mathbf{m})$ & $\mathbf{\Delta H}$ (m) \\
\hline Loop 1 & Starting and Closing Station (XSU100) & 76.377 & 76.383 & -0.006 \\
\hline Loop 2 & Starting and Closing Station (TP1) & 60.912 & 60.903 & 0.009 \\
\hline
\end{tabular}

\section{Analysis of the Gravimetric Geoid Model}

Table 2 and Figures 10a and 10b respectively present the coordinates of the selected points, their corresponding computed local gravimetric geoid heights and the determined geoid model, and their surface and contour plots. The gravimetric geoid heights of the points were computed using the integration of modified Stokes' integral. The gravity anomalies of the points used for the computation of the local gravimetric geoid heights of the points were computed on the Clarke 1880 ellipsoid which is the ellipsoid adopted for local geodetic computation in a. From Table 2, it is seen that the determined geoid model (mean of geoid heights) is $2.066 \mathrm{~m}$. This implied that to convert ellipsoidal heights of points to orthometric heights in Benin City, 2.066m will be subtracted from the ellipsoidal heights of the points. Also, from Figures 10a and $10 \mathrm{~b}$, it is seen that at the centre, there are depressions with small cliffs closed to them while at some distances from the centre there are small depressions which implies that the geoid heights of the study area vary with no constant value.

Table 2: Coordinates of the Selected Points and their Respective Local Gravimetric Heights

\begin{tabular}{|c|c|c|c|}
\hline STATION & Northing & Easting & $\begin{array}{c}\text { Free Air Geoid Height, N Corrected for } \\
\text { Combined Topographic Effect }\end{array}$ \\
\hline XSU92 & 257998.9800 & 357763.3720 & 2.086 \\
\hline RR01 & 257885.3227 & 355124.0166 & 2.420 \\
\hline SR01 & 254586.4919 & 355927.3773 & 1.588 \\
\hline SR02 & 253034.8393 & 356093.6672 & 1.978 \\
\hline SR04 & 249754.3940 & 356486.6091 & 2.520 \\
\hline SR05 & 245976.7564 & 356615.1406 & 2.802 \\
\hline SR06 & 244918.0916 & 356628.3396 & 3.266 \\
\hline XSU100 & 252357.6855 & 356143.1412 & 2.098 \\
\hline AR01 & 257163.2838 & 354191.2450 & 0.685 \\
\hline AR02 & 256084.6701 & 352774.2792 & 0.720 \\
\hline AR03 & 253855.5374 & 351456.5724 & 1.436 \\
\hline AR04 & 253286.3364 & 351007.1375 & 1.439 \\
\hline UU01 & 267318.6942 & 352896.8470 & 4.658 \\
\hline UU02 & 265145.3515 & 353468.5482 & 3.498 \\
\hline UU03 & 262403.8368 & 354173.5295 & 1.981 \\
\hline UU04 & 260409.1199 & 354602.6925 & 1.276 \\
\hline UU05 & 259407.1043 & 355613.0973 & 1.346 \\
\hline UU06 & 258099.7270 & 356379.9681 & 1.489 \\
\hline UU07 & 257012.1709 & 355964.2081 & 1.329 \\
\hline UU08 & 256422.9868 & 355521.4167 & 1.263 \\
\hline AD01 & 260514.8753 & 359958.1194 & 2.986 \\
\hline & & & \\
\hline
\end{tabular}




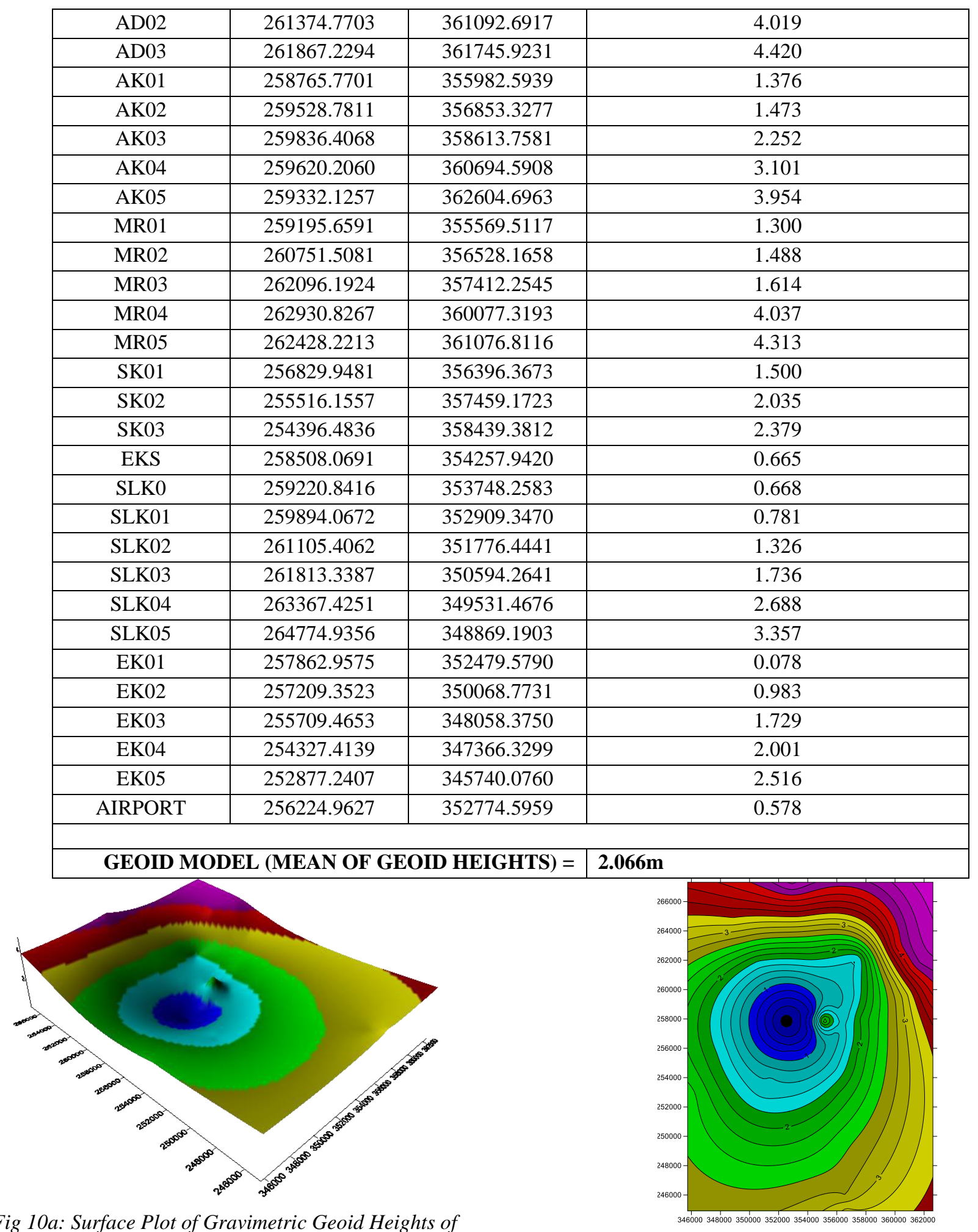
the Selected Points

Fig 10b: Contour Plot of Gravimetric Geoid Heights of the Selected Points

3.4 Analysis of the Accuracy/Validation of the Determined Geoid Model

Table 3 and Figure 11 respectively present the computed RMSE of the geoid model and the plot of the model and the observed orthometric heights. This was 
done to present the consistency, as well as the reliability of the determined geoid model. It can be seen from Table 3 that the computed RMSE, as well as the accuracy of the determined gravimetric geoid model, is $0.412 \mathrm{~m}$. This implies that ellipsoidal heights can be converted to orthometric height with an accuracy of $41 \mathrm{~cm}$ using the determined geoid model. It can also be seen from Figure 11 that the model and the observed orthometric heights of the validation points/stations are identical in shape which also implies the high reliability, as well as consistency of the determined gravimetric geoid model.

Table 3: Observed and Model Orthometric Height, and Model RMSE/Accuracy

\begin{tabular}{|c|c|c|c|c|c|c|}
\hline & DGPS \\
$\begin{array}{c}\text { STATIO } \\
\text { N }\end{array}$ & $\begin{array}{c}\text { ELLIPSOIDA } \\
\text { L HEIGHT (m) }\end{array}$ & $\begin{array}{c}\text { GEOID } \\
\text { MODE } \\
\text { L (m) }\end{array}$ & $\begin{array}{c}\text { MODEL } \\
\text { ORTHOMETRI } \\
\text { C HEIGHT (m) }\end{array}$ & $\begin{array}{c}\text { DIFF. B/W } \\
\text { OBSERVED } \\
\text { ORTHOMETRI } \\
\text { C HEIGHT (m) }\end{array}$ & $\begin{array}{c}\text { MODEL \& } \\
\text { KNOWN } \\
\text { ORTHOMETRIC } \\
\text { HEIGHTS (m) }\end{array}$ & $\begin{array}{c}\text { DIFF. } \\
\text { SQUARE } \\
\text { D }\end{array}$ \\
\hline XSU92 & 106.668 & 2.066 & 104.602 & 105.441 & 0.839 & 0.704 \\
\hline XSU100 & 78.399 & 2.066 & 76.333 & 76.377 & 0.044 & 0.002 \\
\hline TP1 & 63.122 & 2.066 & 61.056 & 60.912 & -0.144 & 0.021 \\
\hline TP2 & 53.326 & 2.066 & 51.260 & 51.605 & 0.345 & 0.119 \\
\hline TP3 & 64.069 & 2.066 & 62.003 & 62.068 & 0.065 & 0.004 \\
\hline
\end{tabular}

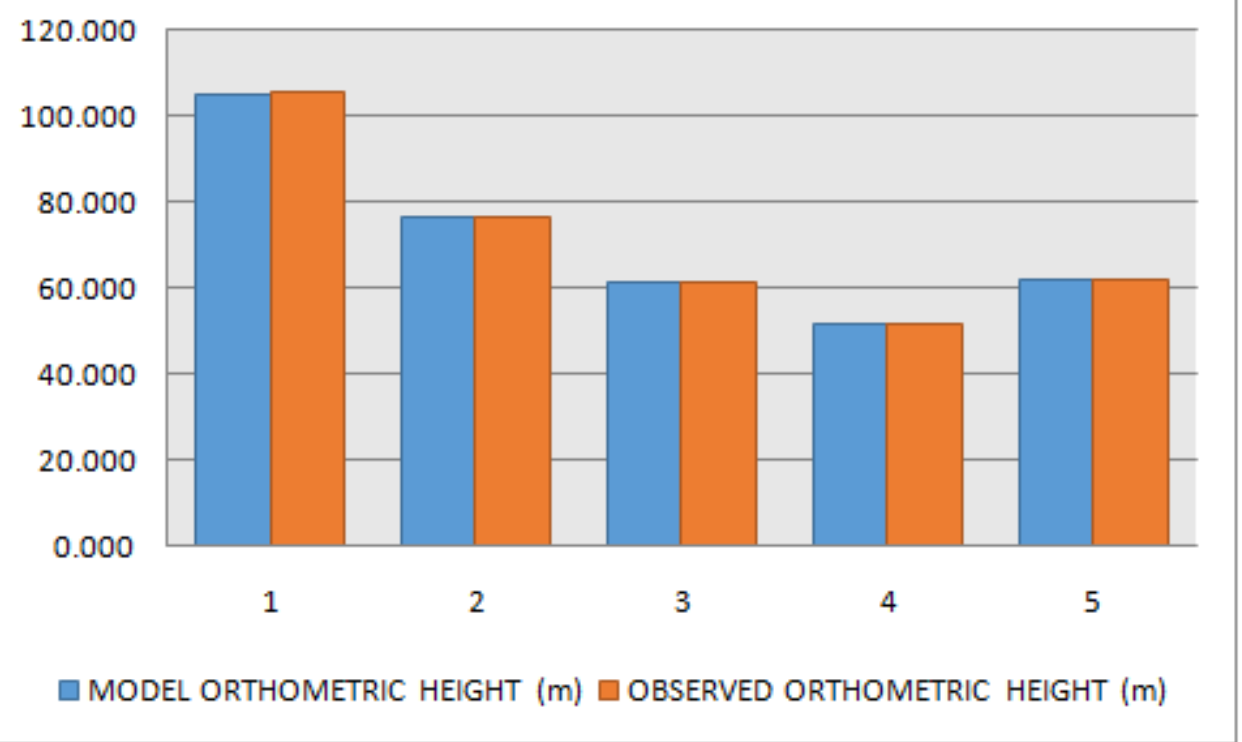

Fig. 11: Validation Points Model and Observed Orthometric Heights

IV. CONCLUSIONS AND RECOMMENDATIONS

1. The local geoid model of Benin City has been determined to be $2.066 \mathrm{~m}$ using the gravimetric method of integration of modified Stokes formula.

2. The study has shown that ellipsoidal heights can be converted to orthometric heights with an accuracy of $0.412 \mathrm{~m}$ using the determined geoid model.

3. It is recommended that the determined geoid model should be applied whenever ellipsoidal heights are to be converted to practical, as well as orthometric heights in Benin City.

4. It is also recommended that the use of assumed, as well as handheld GPS receiver heights should be totally abolished as this study has established the local geoid model of Benin City.

\section{REFERENCES}

[1] Aziz, N., Majid, B. and Jörg, E. (2010). Gravity and Magnetic Data Acquisition Over a Segment of the MøreTrøndelag Fault Complex. NGU Report 2010.049.

[2] Dawod, D. M. (1998). A National Gravity Standardization Network for Egypt. Published Ph.D Dissertation of the Department of Surveying Engineering, Shoubra Faculty of Engineering, Zagazig University. https://www.academia.edu/794554/The_egyptian_national _gravity_standardization_network_ENGSN97_. Accessed 20th September 2019. 
[3] Eteje, S. O. (2015). Determination of the Local Geoid Model Using the Geometric (GPS/Levelling) Method for Evboriaria in Benin City, Edo State. Unpublished MSc Thesis of the Department of Surveying and Geoinformatics, Nnamdi Azikiwe University, Awka.

[4] Eteje, S. O. and Oduyebo, F. O. (2018): Local Geometric Geoid Models Parameters and Accuracy Determination Using Least Squares Technique. International Journal of Innovative Research and Development (IJIRD), Vol. 7, No 7, pp 251-257.DOI: 10.24940/ijird/2018/v7/i7/JUL18098.

[5] Eteje, S. O., Oduyebo, O. F. and Olulade, S. A. (2018). Procedure for the Determination of Local GravimetricGeometric Geoid Model. International Journal of Advances in Scientific Research and Engineering, Vol. 4, No. 8, pp 206-214. DOI: 10.31695/IJASRE.2018.32858.

[6] Eteje, S. O., Oduyebo, O. F. and Oluyori, P. D. (2019). Modelling Local Gravity Anomalies from Processed Observed Gravity Measurements for Geodetic Applications. International Journal of Scientific Research in Science and Technology, Vol. 6, No. 5, pp 144-162. DOI: 10.32628/IJSRST196515.

[7] Eteje, S. O., Oduyebo, O. F. and Oluyori, P. D. (2019). Procedure for Coordinates Conversion between NTM and UTM Systems in Minna Datum Using AllTrans and Columbus Software. International Journal of Scientific Research in Science and Technology, Vol. 6, No. 5, pp 128-143. DOI: 10.32628/IJSRST196517.

[8] Eteje, S. O., Oduyebo, O. F. and Ono, M. N. (2019). Derivation of Theoretical Gravity Model on the Clarke 1880 Ellipsoid for Practical Local Geoid Model Determination. Scientific Research Journal (SCIRJ), Vol. 7, No 2, $\quad$ pp 12-19. DOI: 10.31364/SCIRJ/v7.i2.2019.P0219612.

[9] Eteje, S. O., Ono, M. N. and Oduyebo, O. F. (2018). Practical Local Geoid Model Determination for Mean Sea Level Heights of Surveys and Stable Building Projects. IOSR Journal of Environmental Science, Toxicology and Food Technology (IOSR-JESTFT), Vol. 12, No. 6, pp 3037.

[10] Featherstone, W. E. and Olliver, J. G. (1997). A Method to Validate Gravimetric-Geoid Computation Software Based on Stokes's Integral Formula. Journal of Geodesy, Vol. 71, pp 571-576.

[11] Helskanen, W. A. and Moritz, H. (1967): Physical Geodesy. Freeman and Company, San Francisco, Geoid Modelling and Height Determination for Engineering Applications. www.abu.edu.ng/publications/2009-07-11122210 2930.pdf. Accessed January 26, 2018.

[12] Kao, S., Ning, F., Chen, C. and Chen, C. (2017): Using Particle Swarm Optimization to Establish a Local Geometric Geoid Model. Boletim de Ciências Geodésicas, Vol. 23, No. 2, pp. 327-337.

[13] Kotsakis, C. (2008): Transforming Ellipsoidal Heights and geoid Undulations between Different Geodetic Reference Frames. Journal of Geodesy, Vol. 82, No. 4, Pp 249-260.
[14] Kotsakis, C., Sideris, M. G. (1999): On the Adjustment of Combined GPS/Levelling/ Geoid Networks. Journal of Geoid Vol. 73, pp 412-421.

[15] Krynski J. And Lyszkowicz, A. (2006): Fitting gravimetric Quasigeoid Model to GPS/Levelling Data in Poland. First International Symposium of the International Gravity Field Service, Istanbul, Turkey.

[16] Kuczynska-Siehien, J., Lyszkowicz, A. and Birylo, M. (2016). Geoid Determination for the Area of Poland by the Least Squares Modification of Stokes' Formula. Acta Geodyn. Geomater, Vol. 13, No. 1, Pp 19-26.

[17] Oluyori, P. D., Ono, M. N. and Eteje, S. O. (2018). Comparison of Two Polynomial Geoid Models of GNSS/Levelling Geoid Development for Orthometric Heights in FCT, Abuja. International Journal of Engineering Research and Advanced Technology (IJERAT), Vol. 4, No. 10, pp 1-9. DOI: 10.31695/IJERAT.2018.3330.

[18] Oluyori, P. D., Ono, M. N. and Eteje, S. O. (2018). Computations of Geoid Undulation from Comparison of GNSS/Levelling with EGM 2008 for Geodetic Applications. International Journal of Scientific and Research Publications, Vol. 8, No. 10, pp 235-241. DOI: 10.29322/IJSRP.8.10.2018.p8230.

[19] Ono, M. N. (2009): On Problems of Coordinates, Coordinate Systems and Transformation Parameters in Local Map Production, Updates and Revisions in Nigeria. FIG Working Week, Eilat, Israel.

[20] Seager, J., Collier, P., and Kirby, J. (1999): Modelling Geoid Undulations with an Artificial Neural Network. IIEEE, International Joint Conference, Volume 5, pp 3332 -3335 .

[21] Shrivastava, P., Sahoo, L. and Stalin, M. (2015). Geoid Models for Indian Territory. IJSRSET, Vol. 1 No. 4, Pp 180-187.

[22] Sjöberg, L. E. (2000). On the Topographic Effects by the Stokes Helmert Method of Geoid and Quasi-Geoid Determinations. Journal of Geodesy, Vol. 74 No. 2, Pp 255-268. DOI: 10.1007/s001900050284 in KuczynskaSiehien, J., Lyszkowicz, A. and Birylo, M. (2016). Geoid Determination for the Area of Poland by the Least Squares Modification of Stokes' Formula. Acta Geodyn. Geomater, Vol. 13, No. 1, Pp 19-26.

[23] Yilmaz, M. and Arslan, E. (2006): Application of Fuzzy Logic Theory to Geoid Height Determination. First International Symposium of the International Gravity Field Service, Istanbul, Turkey. 